\title{
Analysis of Roll Wear Costs During Multi-Strand Rolling of Ribbed Bars Using New Slitting Pass System
}

\author{
Dominika Strycharska \\ Czestochowa University of Technology, Poland
}

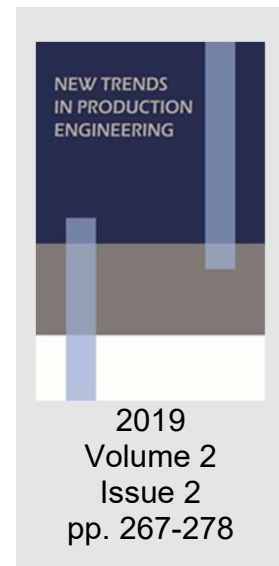

Date of submission to the Editor: 09/2019

Date of acceptance by the Editor: 11/2019

\section{INTRODUCTION}

Every enterprise, regardless of the industry or type of business, strives to achieve a specific goal, which is profit. The overriding goal of each company is to achieve market success and the largest share in the market (Repetowski, 2010).

An enterprise (organization) operating under its own conditions (location, production technology and organization, employee qualifications, etc.) uses (consumes) resources to achieve certain benefits. Among the resources the following can be distinguished: human, physical, financial, or information resources. Their presence, and the possibility to use them depend on the purpose of the company. Resources (materials, machines, devices, buildings, qualified employees, new technologies, etc.) are involved for a long time or purchased as needed (Repetowski, 2010).

The company's costs, also called prime costs, arise as a result of deliberate use of the resources available in the organization. The consumption cost of each resource can be expressed as the product of the physical quantity of the consumed resource and the unit price of the resource (Gabrusewicz, 2000; Karpiński, 2004).

The basic cost components are (Nowak, 2000):

- usage of fixed assets ("depreciation of fixed assets");

- consumption of materials and energy;

- commitment of human work in the form of paid wages;

- use of external services (e.g. transport, renovation, banking, etc.)

Enterprises producing ribbed bars for concrete reinforcement, wanting to be competitive and meet the expectations of customers, manufacture products with an appropriate structure, appropriate shape and dimensions. Customers also require low-priced products, which is why these companies are looking for ways to reduce production costs, thanks to which they will be able to lower the price of ribbed bars. One of these methods is to implement the multi-strand rolling process (Dyja et al., 2010; Mróz, 2010). 
The use of this technology allows one billet to be divided into two, three, four or five strands in the rolling mill train, from which it is possible to simultaneously roll ribbed bars corresponding to the number of strands. In the technology of multi-strand rolling of bars in the rolling line, a special pass system is used, which is designed to form the strip into separate strands. This process takes place in special forming, pre-slitting and slitting passes. For final separation of the strip into separate strands special separation equipment is used, in which the breaking of the bridge connecting the strands is carried out by means of nondriven separating rolls (Stefanik, 2008; Turczyn \& Michałowski, 1999; Turczyn et al. 2014).

During the process of multi-strand rolling of ribbed bars in the rolling mill train, individual passes of the rolling mill train wear out, in particular slitting passes and their knife parts, due to the large pressures that occur on them. The wear of these passes may lead to a change in the cross-section of the strip, and in particular the bridge(s) connecting the individual strands, which may lead to interruption of the continuity of the process (Byon et al., 2017; Byon et al., 2009; Madej et al., 2009; Mróz, 2008; Na et al., 2011; Szota et al., 2010).

Metallurgical rolls are one of the most expensive tools used in metal forming processes, which is why companies are looking for new technological and construction solutions that will increase their durability, and in turn will affect process efficiency and reduce production costs (Lambiase, 2014; Mróz, 2008; Na et al., 2011; Turczyn \& Michałowski, 1999).

For many years, research has been carried out that seeks to optimize the shape of the tools used in the processes of plastic processing and to use new materials for these tools to increase their durability, and thus prolong the rolling campaign, reduce downtime, etc. This is because all these elements constitute unnecessary costs that affect the price of the finished product and which can be reduced (Mróz, 2008; Mróz, 2009; Strycharska et al., 2017).

The aim of the work was to determine the influence of the applied slitting pass system on the wear cost of rolls used in the process of three-strand rolling of ribbed bars with a diameter of $16 \mathrm{~mm}$. In the theoretical studies, both a classic pass system - with two slitting passes as well as a new one - using three slitting passes were taken into account. Experimental tests, which were carried out in industrial conditions, allowed the actual pass wear after the rolling campaign to be determined.

\section{RESEARCH METHODOLOGY}

Theoretical and experimental research on the rolling process of ribbed bars with a diameter of $16 \mathrm{~mm}$ was aimed at increasing the durability of slitting passes, whose task is to shape the strip for the right number of strands. These tests were carried out for a D350 18-stand continuous bar rolling mill. The scheme of the pass system used in the analysed bar mill is shown in Fig. 1 (Strycharska, 2015). Using the principles adopted in (Mróz, 2008; Strycharska, 2015), a new slitting pass system (with three slitting passes and a special edging pass) was 
developed for rolling ribbed bars with a diameter of $16 \mathrm{~mm}$ in three-strand technology (Fig. 2).

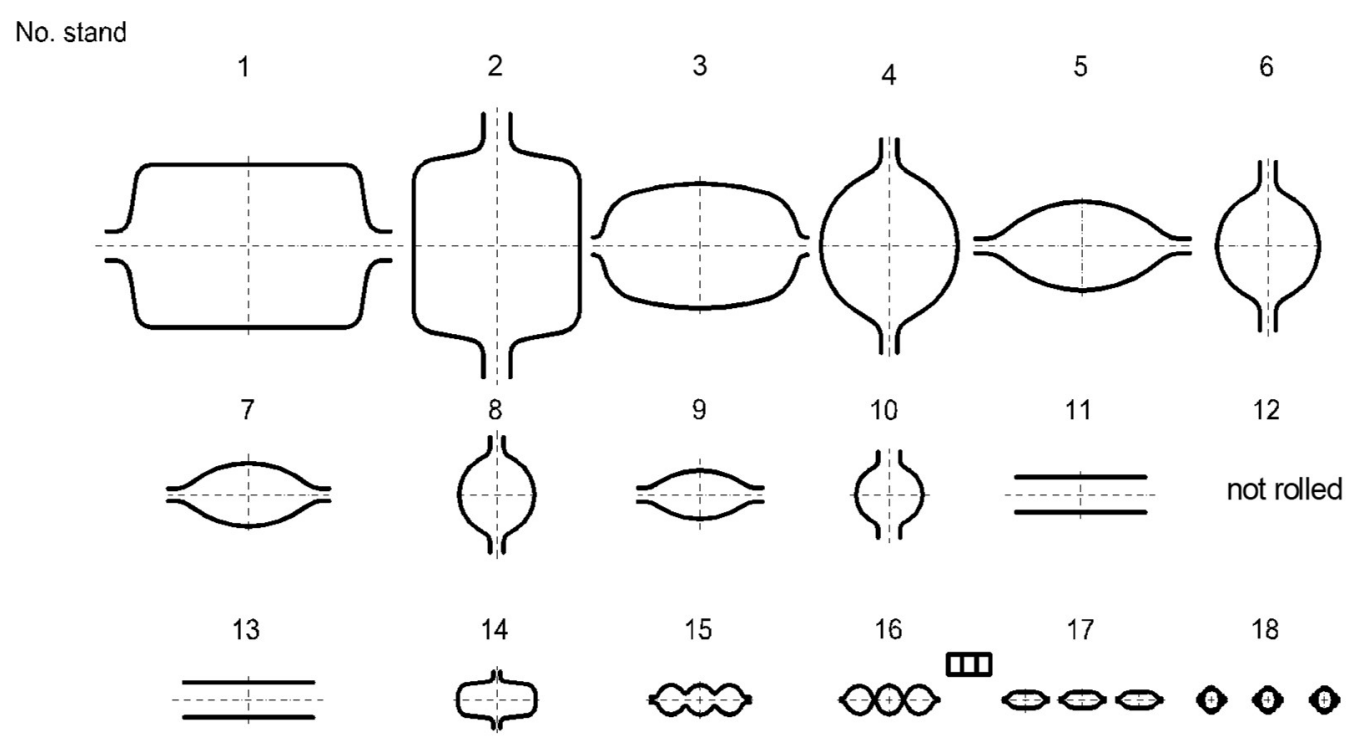

Fig. 1 Schedule of classical three-strand rolling process of $16 \mathrm{~mm}$ reinforcement bar Source: (Strycharska et al., 2017)

In the currently used slitting pass systems, 2 slitting passes are most commonly used: a pre-slitting pass and slitting pass, whose task is to form bridges connecting particular strands of appropriate height, i.e. ones that will provide longitudinal separation of the strip into separate strands by means of special separating equipment, wherein tearing of the bridge connecting the strip takes place by means of non-driven separation rolls. The rolled strip is separated by the separation rolls as a result of the resistance force that drives these rolls.

Diagrams of separating a multi-strand strip into 3 strands using non-driven separation rolls are shown in Fig. 2.

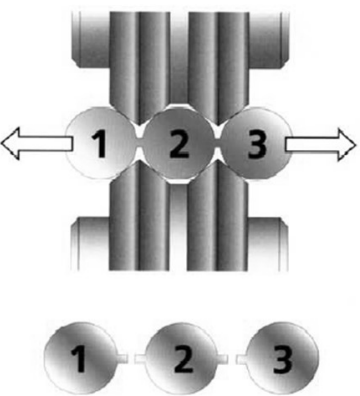

Fig. 2 Diagram of longitudinal strip separation into three strands using Source: (Mróz, 2008) non-driven separation rolls

When separating a three-strand strip using non-driven separation rolls, the external strands (No. 1 and 3) move freely in opposite directions. The inner strand (No. 2), on the other hand, does not move, because the movement of the strand in a direction transverse to the rolling direction is limited by the side surfaces of the separation roll (Mróz, 2008). Due to the use of 2 slitting passes 
in the currently employed pass system, there must be a significant reduction in the strip height, which affects their rapid wear (Fig. 3a).

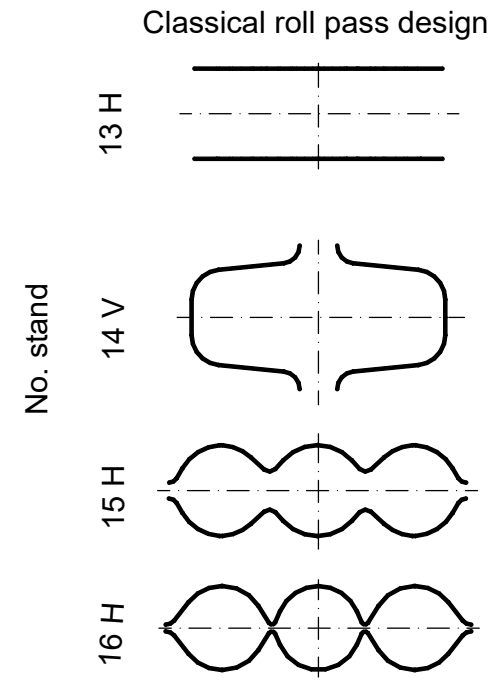

a)

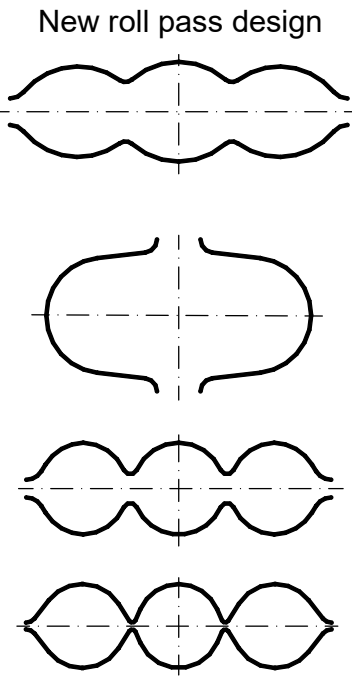

b)

Fig. 3 Roll pass design to three-strands rolling process of $16 \mathrm{~mm}$ ribbed bar:

Source: (Strycharska et al., 2017)

a) classical, b) new

The main aim of using the new slitting pass system in the finishing stands group of the continuous bar rolling mill was to reduce the roll wear cost (Fig. 3b).

The first pre-slitting pass, whose task is to separate the strip into 3 strands, was introduced in place of the "flat drum" type pass in Stand 13. The traditional edging pass (with a flat bottom) in Stand 14 was changed to a edging pass with a round bottom, which is used to produce flat bars with rounded corners. Applying such a pass will provide a greater possibility of controlling the width of the pre-divided strip in Stand 15, which is particularly important during vertical displacement of the strip axis relative to the vertical axis of the pre-slitting pass. Changes were also made in the pre-slitting pass. Thanks to the pre-slitting pass already in Stand 13, it was possible to increase the height of the knife parts of the pass grooves. This shape of pass in Stand 15 will significantly relieve the slitting pass in Stand 16 compared to the currently used pass system. The slitting pass in both systems is the same (Strycharska, 2015).

\section{NUMERICAL MODELLING OF ROLLING PROCESS OF RIBBED BARS IN SLITTING PASSES}

To determine the costs related to roll wear, it is necessary to determine their wear after rolling a specified batch of products. In practice, this is a very difficult task, hence in work (Szota et al., 2015), a methodology was developed which, using FEM modelling, allows the actual shape of the rolls to be determined and as well as their service life.

Fig. 4 presents the results of numerical calculations of the frictional force unit of work determined using the computer program Forge $2011 \AA$. These tests were carried out both for the systems currently used with 2 slitting passes as well as the new one with 3 slitting passes (Strycharska et al., 2017). 
The designed slitting pass system influenced a change in the frictional force unit of work values at the contact surface of the strip with the pass for Stands 13-16.

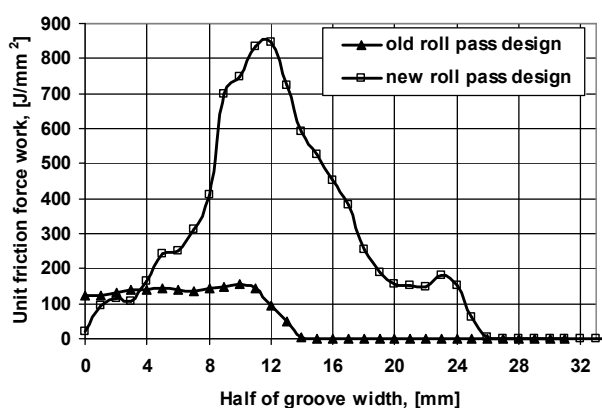

a)

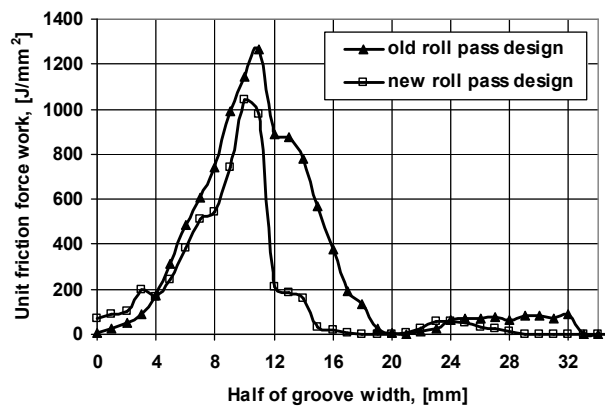

c)

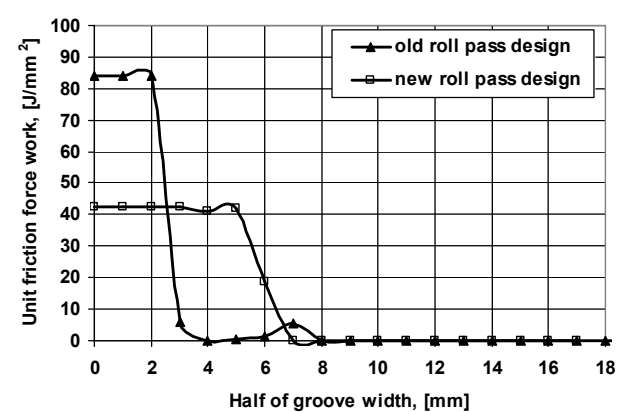

b)

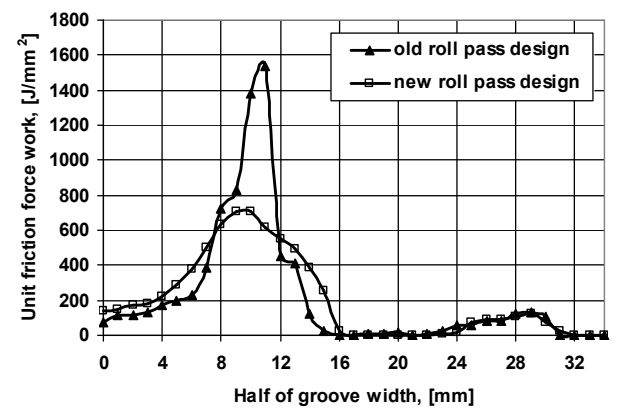

d)

Fig. 4 Distribution of unit friction force work during three-strands rolling process of $16 \mathrm{~mm}$ ribbed Source: (Strycharska et al., 2017)

Comparison of the obtained frictional force unit of work values for the passes in Stand 13 shows that for the new pass - pre-slitting - these values are larger compared to the values obtained for the pass used so far - "flat barrel" (Fig. 4a). The maximum frictional force unit of work value on the surface of the pass currently used was $157 \mathrm{~J} / \mathrm{mm}^{2}$, while on the surface of the new pass, this value increased to $845 \mathrm{~J} / \mathrm{mm}^{2}$.

This is due to the fact that in Stand 13 the first slitting pass was introduced instead of a flat barrel. In the areas where bridges are formed, the strip is the most intensely deformed, hence the wear of these pass elements will be the largest. For the remaining parts of the slitting pass, the obtained frictional force unit of work values are much smaller compared to the values obtained for the knife parts of the pass and approximately correspond to the values obtained for the smooth rolls currently used in this stand.

During strip rolling in Stand 14, the obtained frictional force unit of work values at the contact surface between the strip and the new pass are smaller compared to the values obtained for the currently used pass (Fig. 4b). The maximum frictional force unit of work value on the surface of the currently used pass was $84 \mathrm{~J} / \mathrm{mm}^{2}$, and on the surface of the new pass, this value decreased to $42 \mathrm{~J} / \mathrm{mm}^{2}$. This difference results from changing the edging pass (with a flat bottom) to one with a rounded bottom. The new edging pass affects a more even strip 
deformation. The rounded lateral surface of the strip obtained in Stand 13 corresponds to the rounding in the bottom of the groove of the new edging pass. On the other hand, in the currently used pass system - the rounded side surface of the strip obtained in Stand 13 is deformed by the flat bottom of the groove of the edging pass rolled on the rolls in Stand 14.

In the next passage (Stand 15), the strip is rolled in the first pre-slitting pass (the pass system currently in use) and the second pre-slitting pass (new pass system) (Figure 4c). In both cases, the highest frictional force unit of work values occur in the pass groove areas in which the bridges link individual strands. Using 2 passes pre-forming the bridges (new pass system) reduces the frictional force unit of work in these areas of the pass, compared to the values obtained for the pass system in which only 1 pre-slitting pass was used. The maximum frictional force unit of work value on the surface of the pass currently used was 1268 $\mathrm{J} / \mathrm{mm}^{2}$, while on the surface of the new pass it amounted to $1044 \mathrm{~J} / \mathrm{mm}^{2}$. This difference is due to the fact that already in Stand 13 in the newly designed passes the first slitting pass is used, in which forming of the bridges in the strip begins. Therefore, in this case, in Stand 15, in order to shape bridges of a suitable height, a smaller rolling reduction, can be used in comparison with the rolling reduction used in the pass system with one pre-slitting pass. In this variant, the pass in Stand 15 is the first pass forming the bridges connecting individual strands in the rolled strip (pre-slitting).

In Stand 16 (slitting pass) the final forming of the bridges connecting the individual strands in the multi-strand strip takes place (Figure $4 d$ ). In both analysed systems, the shape and dimensions of this pass are the same. However, the obtained frictional force unit of work values were lower by more than $50 \%$ for the new system of passes in comparison with the values obtained for the slitting pass currently used. The maximum frictional force unit of work value on the surface of the slitting pass for the current system was $1533 \mathrm{~J} / \mathrm{mm}^{2}$, and for the slitting pass used in the new system, this value decreased to 709 $\mathrm{J} / \mathrm{mm}^{2}$. The lower frictional force unit of work value for the slitting pass used in the new system resulted from the fact of using a smaller rolling reduction in the areas of the strip in which the bridges linking individual strands are formed.

This pass in the rolling process is the most responsible for correct separation of the strip, as it is in Stand 16 that final forming of the bridges connecting the individual strands in the strip takes place. The nominal thickness of the bridges connecting individual strands in a rolled strip should be $0.9 \mathrm{~mm}$. Increasing the thickness of these bridges, as a result of excessive wear of the slitting pass, will not ensure proper separation of the strip in the separation rolls. During exploitation of the rolls and wear of the knife parts of the slitting passes, the thickness of the bridges connecting the individual strands increases. Correction of this thickness is done by reducing the gap between the rolls. However, such a change causes a reduction in the cross-sectional area of individual strands and as a consequence, the finished product (ribbed bar) does not meet the requirements of acceptance standards (Strycharska et al., 2017). 
The wear model used in the Forge $2011 \AA$ computer program does not allow quantitative evaluation of roll wear, but only qualitative (comparative) analysis (Figure 4). In order to use the results of the simulation using the simplified Archard model, to quantify the wear of the rolls it is necessary to take into account the wear coefficient, which was determined on the basis of experimental research in work kzuz $=1.4 \cdot 106 \mathrm{~mm}^{3} \cdot \mathrm{mm}-1 \cdot \mathrm{mm}^{-2}$ (Szota et all, 2015).

The conducted research provided information, that the highest pass wear took place in areas where the frictional force unit of work values, shown in Fig. 4, take the highest values.

When comparing the wear of the passes in Stand 13, it should be noted that greater quantitative wear occurs in the newly developed pass - pre-slitting compared to the flat barrel. After rolling $1000 \mathrm{Mg}$ of bars, the wear in the smooth rolls used to date was only $0.04 \mathrm{~mm}$, while in the newly designed pre-slitting pass, it rose to $0.34 \mathrm{~mm}$ in its knife parts. The wear of the pre-slitting pass at the bottom of the groove was comparable to the wear of the smooth rolls used to date. This is due to the fact that in Stand 13, the first slitting pass was introduced instead of a flat barrel. It is the pass in which bridge forming in the strip begins, which requires applying large deformation in these areas of the strip, hence the wear of the pass knife parts will be the largest.

The wear of the edging pass with a flat bottom after rolling $1000 \mathrm{Mg}$ of bars is $0.03 \mathrm{~mm}$, while the using new pass shape (edging pass with rounded bottom) reduces the wear of the bottom of the groove to $0.01 \mathrm{~mm}$. The smaller wear of the new pass is due to the fact that the rounding in its bottom corresponds to the rounded side surface of the strip obtained in Stand 13. In the currently used system - the rounded side surface of the strip obtained in Stand 13 is deformed by the flat bottom of the edging pass in Stand 14 .

In Stand 15, less wear occurs in the newly developed pass, as in Stand 13 preforming of the bridges in the strip takes place, which is connected with the possibility of using a smaller rolling reduction in these areas of the strip in Stand 15. The wear in the currently used pass is $0.43 \mathrm{~mm}$, while in the newly developed pass it is $0.36 \mathrm{~mm}$.

In the slitting pass a significant decrease in the wear of the knife parts of the pass can be noticed by comparing the system of passes used to present (2 slitting passes) with the newly developed system (three slitting passes). The wear in the slitting pass for the current system is $0.47 \mathrm{~mm}$, while employing the new system results in a decrease in wear in the slitting pass to $0.14 \mathrm{~mm}$.

In the pass system used to date, the slitting pass (Stand 16) undergoes the fastest wear, and at the same time it is the most responsible for correct separation of the strip, because in this pass final forming of the bridges connecting the individual strands in the strip takes place. However, in the newly developed pass system, the slitting pass (Stand 16) has been significantly relieved, because the total rolling reduction in the areas of the strip in which the bridges connecting the individual strands are formed, were separated into three passages. Thanks to this, the durability of this pass has significantly increased. In the new system, the most worn pass is the first pre-slitting pass (Stand 13). 
However, this pass does not directly affect division of the strip, so it can be used longer by adjusting the gap between the rolls.

The analysis of roll wear clearly showed the advantage of the new system of slitting passes, ensuring greater durability, which will affect the service life the tools. Using the new system of passes will allow the rolling campaign to be prolonged, thanks to reducing the downtime during which the rolls are replaced, and in turn will reduce the production costs (Szota et all, 2015).

\section{ANALYSIS OF COST OF SLITTING PASS WEAR IN PROCESS OF ROLLING OF RIBBED BARS}

In the process of three-strand rolling of ribbed bars with a diameter of $16 \mathrm{~mm}$, the most expensive and the most responsible tools for their quality are metallurgical rolls. Therefore, their wear is a significant problem in the processes of plastic processing, which forces enterprises to look for new technological and construction solutions that will allow them to increase their durability and thus to reduce production costs.

To analyse the costs of the rolling process of ribbed bars with a diameter of 16 $\mathrm{mm}$ in three-strand technology, only Stands 13-16 were considered, i.e. those for which the new pass system was developed.

The weight of ribbed bars with a diameter of $16 \mathrm{~mm}$ which was rolled in one pass in the currently used pass system, was determined on the basis of data obtained from the analysed mill (Table 1). However, the weight of ribbed bars with a diameter of $16 \mathrm{~mm}$ which can be rolled in one pass (without the need for machining, i.e. its shunting) for the new pass system was determined on the basis of the calculated frictional force unit of work.

Table 1 The weight of the ribbed bars be rolled in one pass for the currently used pass system

\begin{tabular}{|c|c|c|}
\hline Rolling stand number & Type of pass & Weight of bars rolled in one pass, Mg \\
\hline 13 & flat barrel & 3000 \\
\hline 14 & edging & 3000 \\
\hline 15 & pre-slitting & 1770 \\
\hline 16 & slitting & 980 \\
\hline
\end{tabular}

Since no new real data were available for the new pass system (the developed technology had not yet been implemented in the analysed bar continuous rolling mill), it was necessary to determine how much the frictional force unit of work for the new passes would change, compared to the passes currently used, as determined by coefficient $W$, which was defined as:

$$
W=\frac{J_{o}}{J_{N}}
$$

where:

$J_{O}$ - frictional force unit of work obtained for the currently used passes, $\left[\mathrm{J} / \mathrm{mm}^{2}\right]$, $J_{N}$ - frictional force unit of work obtained for new passes, $\left[\mathrm{J} / \mathrm{mm}^{2}\right]$.

This coefficient was substituted in Equation (2), which allowed the authors to determine how much the production in a given rolling stand would change after introducing the new slitting pass system (Table 2). 


$$
W_{P N}=W_{P O} \cdot W
$$

where:

$W_{P O}$ - the weight of bars which was rolled out in the individual stands of the group.

Table 2 The weight of ribbed bars that can be rolled in one pass using the new slitting pass system

\begin{tabular}{|c|c|c|}
\hline Rolling stand number & $W$ coefficient & Weight of bars that can be rolled in one pass $W_{P N}[\mathrm{Mg}]$ \\
\hline 13 & 1.5 & 2655 \\
\hline 14 & 2.0 & 6000 \\
\hline 15 & 1.21 & 2142 \\
\hline 16 & 2.16 & 2117 \\
\hline
\end{tabular}

Based on the data from the analysed continuous rolling mill, it was found that there are 6 passes on the width of the roll barrel and that the rolls can be rolled 6 times before they are completely worn (they will be rolled to the so-called "dead diameter"). These data allow the weight of ribbed bars with a diameter of $16 \mathrm{~mm}$, which can be rolled in one roll assembly, in both pass systems to be determined (Fig. 5).

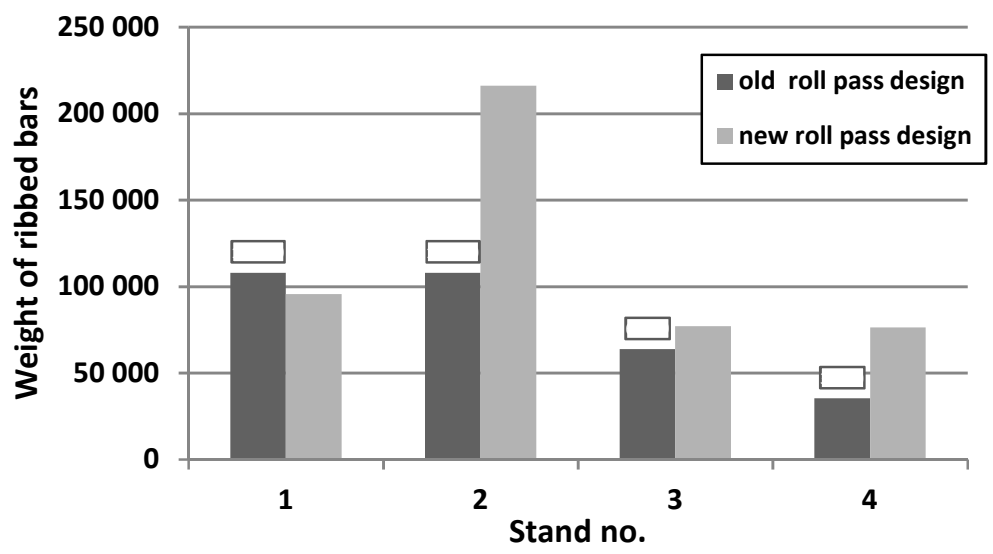

Fig. 5 The weight of ribbed bars which that can be rolled out in pass system currently used and in new pass system

From Fig. 5 it can be concluded that using the new pass system will increase the weight of the bars which can be rolled out in Stands 14-16. Only in Stand 13 will this weight decrease, this is due to introducing the first pre-slitting pass in the analysed stand.

The number of rolls that will be worn during the annual production of ribbed bars in both pass systems is calculated using Equation (3). For the analysis, it was assumed that the average annual production of bars with a diameter of $16 \mathrm{~mm}$ in the analysed mill over the last 3 years amounted to $90,000 \mathrm{Mg}$. Table 3 presents the results of calculations of the number of rolls that will be worn during the production of $90,000 \mathrm{Mg}$ of ribbed bars with a diameter of $16 \mathrm{~mm}$.

$$
L_{K W}=\frac{R_{p}}{L}
$$

where:

$R_{P}$ - annual production of ribbed bars with a diameter of $16 \mathrm{~mm}$ rolled in the analysed mill, [Mg], 
$L$ - weight of bars rolled in 1 roll assembly, [Mg].

Based on the data contained in Table 3, it can be concluded that employing the new pass system will reduce the wear of rolls in Stands 14-16, only in Stand 13 will the roll wear increase.

In the next stage, the cost of purchasing rolls was calculated. Cast iron rolls are used in the analysed mill. In Stands 13-16 the maximum roll diameter is 370 $\mathrm{mm}$, and the weight of one roll is about $500 \mathrm{~kg}$. The cost of purchasing rolls consists in the cost of the raw roll and its machining. The price of $1 \mathrm{~kg}$ of cast iron rolls is $10 \mathrm{PLN}$, which means that the cost of purchasing a raw roll is 5000 PLN.

Table 3 Number of rolls that will be worn during production of $90,000 \mathrm{Mg}$ of ribbed bars with diameter of $16 \mathrm{~mm}$ in currently used pass system and new pass system

\begin{tabular}{|c|l|l|}
\hline Rolling stand number & \multicolumn{1}{|c|}{ Currently used pass system } & \multicolumn{1}{|c|}{ New pass system } \\
\hline 13 & 1 set of rolls $83 \%$ worn & 1 set of rolls $4 \%$ worn \\
\hline 14 & 1 set of rolls $83 \%$ worn & 1 set of rolls $42 \%$ worn \\
\hline 15 & $\begin{array}{l}\text { 1 set of rolls } 100 \% \text { worn, } \\
\text { 2 sets of rolls } 41 \% \text { worn }\end{array}$ & $\begin{array}{l}\text { 1 set of rolls } 100 \% \text { worn, } \\
\text { 2 sets of rolls } 17 \% \text { worn }\end{array}$ \\
\hline \multirow{2}{*}{16} & $\begin{array}{l}\text { 2 sets of rolls } 100 \% \text { worn, } \\
\text { 3 sets of rolls } 55 \% \text { worn }\end{array}$ & $\begin{array}{l}\text { 1 set of rolls } 100 \% \text { worn, } \\
\text { 2 sets of rolls } 18 \% \text { worn }\end{array}$ \\
\hline
\end{tabular}

The cost of machining depends on the type of rolls, i.e. a smooth roll is machined for approx. 4 hours, while a roll with passes is machined on average for approx. 12 hours. The cost of machining man-hours is an average of 72 PLN.

Taking into account the above data, the cost of the rolls was calculated using Equation (4). On this basis, the cost of preparing a smooth roll, which amounts to 5288 PLN (pass system currently used - Stand 13), and the cost of preparing rolls with passes, which amounts to 5864 PLN (the pass system currently used - Stands 116 PLN and the new pass system - Stands 13-16).

$$
\mathrm{KPW}_{\mathrm{PW}} \mathrm{MWw} \cdot \mathrm{C}+I_{R} \cdot C_{R}
$$

where:

Mww - weight of the roll, [kg],

$C$ - purchase cost of $1 \mathrm{~kg}$ of raw roll, [PLN],

$I_{R}$ - roll machining time (number of man-hours), [hrs.],

$C_{R}-$ cost of man-hours, [PLN].

The cost of the rolls used to roll $90000 \mathrm{Mg}$ of ribbed bars with a diameter of 16 $\mathrm{mm}$, which corresponds to their annual production in the analysed mill was calculated using Equation (5).

$$
K_{Z P}=K_{P W} \cdot L_{K W}
$$

Figure 6 shows the calculated costs of roll wear for the currently used pass system and for the new pass system.

To sum up, to produce $90,000 \mathrm{Mg}$ of ribbed bars with a diameter of $16 \mathrm{~mm}$ in three-strand technology, using the pass system currently in use, the cost of roll wear will amount to 64954 PLN, while using the new pass system, this cost will decrease and amount to 43510 PLN. 


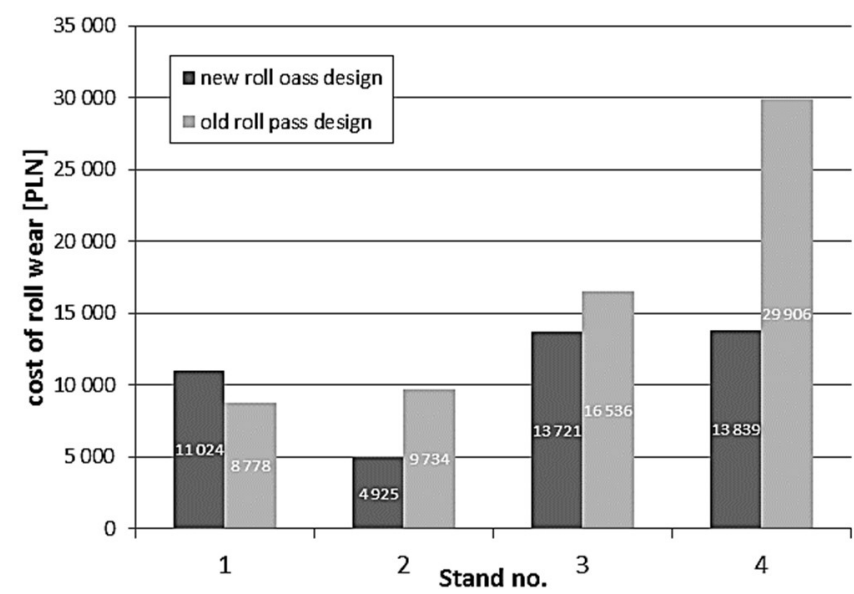

Fig. 6 Cost of roll wear used to produce $90,000 \mathrm{Mg}$ of ribbed bars with diameter of $16 \mathrm{~mm}$ in currently used pass system and new pass system

\section{CONCLUSIONS}

Many modern enterprises base their strategy on assumptions regarding savings of raw materials, energy, fuels, waste minimization or lowering production costs. Using tools in production processes is necessary, and the cost of their acquisition has a significant impact on the final price of the product. Therefore, new technologies should be devised to reduce production costs due to reduce tool wear.

In the process of three-strand rolling of ribbed bars with a diameter of $16 \mathrm{~mm}$, the most expensive and at the same time the most responsible tool for their quality are metallurgical rolls. Their wear is a significant problem in the processes of plastic processing, which forces enterprises to look for new technological and construction solutions.

Applying three-strand technology of the new pass system in the production of ribbed bars with a diameter of $16 \mathrm{~mm}$ affects a reduction in the wear cost of these passes by 21,444 PLN (a decrease of about 33\%) per year.

\section{REFERENCES}

Byon, S. M., Kim, S. I. and Lee Y. (2017). A semi analytical model for predicting the wear contour in rod rolling process. Journal of Materials Processing Technology, 191, pp. 306-309.

Byon, S.M., Na, D. H. and Lee, Y. (2009). Effect of roll gap adjustment on exit cross sectional shape in groove rolling-Experimental and $\mathrm{FE}$ analysis, Journal of Materials Processing Technology, 209 (9), pp. 4465-4470.

Dyja, H., Mróz, S. and Turczyn, St. (2010). The process of ribbed bar rolling with longitudinal band separation. In: Conference MEFORM, 80 Jahre Walzwerks - und Werkstoff technologie, Freiberg, pp. 317-327.

Gabrusewicz, W., Kamela-Sowińska A., Poetschke H., Rachunkowość zarządcza, Warszawa, 2000 (PWE).

Karpiński, T. (2004) Inżynieria Produkcji. Warszawa: Wydawnictwo Naukowo Techniczne.

Lambiase, F. (2014) Prediction of geometrical profile in slit rolling pass, The International Journal of Advanced Manufacturing Technology, 71, pp. 1285-1293.

Madej, Ł., Węglarczyk, S. and Pietrzyk, M. (2009). Analiza wpływu parametrów cyklu produkcyjnego elementów złącznych na zużycie narzędzi, Hutnik - Wiadomości Hutnicze, 8: pp. 620-622. 
Mróz, S. (2008). Proces walcowania prętów z wzdłużnym rozdzielaniem pasma. Seria Monografie 138. Częstochowa: Wydawnictwo Politechniki Częstochowskiej.

Mróz, S. (2009). Modification of the roll pass design to the bar rolling process with longitudinal band separation. Archives of Metallurgy and Materials, 54, pp. 597605.

Mróz, S. (2010). New Roll Pass Design to the Bar Rolling Process Using Longitudinal Slitting Passes. Solid State Phenomena, 165, pp. 310-315.

$\mathrm{Na}, \mathrm{D}$. H., Cho, S. H. and Lee Y. (2011). Experimental and numerical studies for the forming groove and separating groove design in slit rolling process. Journal of Mechanical Science and Technology, 25 (9), pp. 2439-2446.

Nowak, E. (2000). Rachunek kosztów. Wrocław: Ekspert.

Repetowski, R. (2010). Konkurencyjność przedsiębiorstwa w dobie globalnego kryzysu finansowego. Przedsiębiorczość - Edukacja, 6, pp. 92-100.

Stefanik, A. (2008). Slitting criterion for various rolling speeds in MSR rolling process. Journal of Achievements in Materials and Manufacturing Engineering, 27 (1), pp. 91-94.

Strycharska, D. (2015) The technical and economic aspects of multi-strand ribbed bar rolling using the new system of passes, Ph.D., Czestochowa University of Technology.

Strycharska, D., Szota, P. and Mróz, S. (2017) Increasing the durability of separating rolls during rolling ribbed bars in the three-strand technology. Archives Metallurgy and Materials. 62(3), pp. 1535-1540.

Szota, P., Mróz, S., Stefanik, A. and Dyja, H. (2011). Numerical modelling of the working rolls wear during rods rolling process. Archives of Metallurgy and Materials, 56 (2),pp. 495-501.

Szota, P., Strycharska, D., Mróz S. and Stefanik A. (2015). Analysis of rolls wear during the ribbed bars multi-slit rolling process. Archives of Metallurgy and Materials, 60 (2), pp. 815-820.

Turczyn, S. and Michałowski, M. (1999) Walcowanie prętów okrągłych z wielokrotnym podziałem wzdłużnym pasma „multi slit rolling”. Hutnik - Wiadomości Hutnicze, 1, pp. 8-12.

Turczyn, S., Dziedzic, M. and Kuźmiński, Z. (2014). A study on design of slitting passes used for rebar rolling, In: Conference METAL 2014, Brno, pp. 303-308.

\begin{abstract}
.
The paper presents a modification of the slitting pass system, which ensured a reduction in roll wear during three-strand rolling of ribbed bars with a diameter of $16 \mathrm{~mm}$, and thus reduced the associated costs. The theoretical and experimental research on the rolling process of ribbed bars with a diameter of $16 \mathrm{~mm}$ rolled in three-strand technology was carried out on a D350 18-stand continuous bar rolling mill conditions. To determine the cost of slitting pass wear, the results of numerical calculations of the frictional force unit of work obtained using the Forge $2011 \circledR$ computer program was used, as well as empirical calculations.
\end{abstract}

Keywords: slitting passes, wear of rolls, costs, FEM 